\title{
Immediate and Delayed Effects of Using a Classroom Case Exemplar in Teacher Education: The Role of Presentation Format
}

\author{
Roxana Moreno and Alfred Valdez \\ University of New Mexico
}

\begin{abstract}
Students learned teaching principles either with or without (control group) the presentation of a classroom exemplar in video or text format. Across 2 experiments, the video group produced higher transfer scores and affective ratings than the other groups. Four weeks later, the video group recalled more information about the exemplar than the text group, but no treatment effects were found on transfer. Qualitative analyses (Experiment 2) showed that the video group produced a significantly larger number of modeled behaviors in the transfer test than the text (immediate) and control (immediate and delayed) groups. Results encourage using classroom video exemplars to promote students' affect and retention, but suggest that additional pedagogies are needed to promote longer term transfer of theory into practice.
\end{abstract}

Keywords: exemplars, modeling, video, teacher education, learning

How can we help prospective teachers effectively apply principles learned in educational psychology courses to classroom experiences? One promising technique consists of using classroom exemplars during instruction: the presentation of a classroom scenario that illustrates how to apply the learned concepts to the teaching practice (Laframboise \& Griffith, 1997). Using classroom cases as exemplars in teacher education has the advantages of demonstrating how knowledge about teaching and learning can be applied to real classroom situations and providing opportunities for student teachers' discussion and elaboration (Barnett, 1991; Barnett \& Tyson, 1999; van den Berg, Jansen, \& Blijleven, 2004). The goal of this research was to examine whether the presentation of a classroom case exemplar in either text or video format would affect students' learning perceptions and their ability to transfer educational psychology principles to novel classroom situations.

To this end, in two experiments, we compared the learning outcomes and perceptions of students who participated in a classroom lecture about two different educational psychology topics, either with or without the presentation of a classroom case exemplar. Students were randomly assigned to one of three treatment groups. One group watched a video case exemplar during instruction (video group), a second group read a corresponding narrative during instruction (text group), and a third group spent the same amount of time reviewing the topic without the presentation of the case exemplar (control group). To investigate whether the presentation of the classroom case exemplar had immediate and delayed learning effects, we administered retention and transfer tests at two

Roxana Moreno and Alfred Valdez, Educational Psychology Program, University of New Mexico.

This material is based on work supported by National Science Foundation Grant 0238385 and Eastern New Mexico Center for Teaching Excellence EUIRG Grant 15691. Any opinions, findings, and conclusions or recommendations expressed in this material are those of the authors and do not necessarily reflect the views of the funding agencies.

Correspondence concerning this article should be addressed to Roxana Moreno, Educational Psychology Program, Simpson Hall 123, University of New Mexico, Albuquerque, NM 87123. E-mail: moreno@unm.edu different times: immediately after the treatment and 4 weeks later (during the last week of the semester).

Classroom Cases: Definition, Instructional Functions, and Research

The case idea has been implemented as early as 1920 in some schools in the United States, and the development and use of new case materials in teaching concepts and problem-solving strategies are increasing trends in education (Sykes \& Bird, 1992). Cases are used regularly for different instructional purposes in many disciplines, including medicine, law, business, and teacher education (Copeland \& Decker, 1996; Kolodner \& Guzdial, 2000). Despite the lack of consensus about the exact definition of a case (Koehler, 2002, Shulman's (1992) description is probably one of the most widely accepted within the educational field and the one that we follow in this research: A case is "an instance of a larger class, an example of a broader category" (p. 17).

What are some instructional functions of classroom cases? Much of the dialogue about reforming education during the past decade has focused on the limited preparation students receive to facilitate their transition from school to work (Sears \& Hersh, 1998), with much attention given to the need for replacing inert knowledge (Whitehead, 1929) with learning in contextualized, meaningful settings (Borko \& Putnam, 1998; Putnam \& Borko, 2000). Students of teaching are not an exception. Many preservice teachers experience a fragmented and superficial curriculum characterized by inadequate time to connect theory and practice (Goodlad, 1990; Holmes Group, 1995; Merseth, 1999). Applying the theories once learned in traditional teacher education courses to practice poses the greatest challenge to new teachers because of the complexity of the classroom environment. Therefore, a first important function of cases in teacher education is to help prospective teachers bridge theory and practice by illustrating how knowledge about teaching and learning can be applied to real classroom situations (Barnett, 1991; Merseth, 1991 van den Berg et al., 2004). A second function of cases in teacher education consists of using cases as tools to promote problem-based learning 
(Wilkerson \& Gijselaers, 1996). Here, students apply principles and theories to analyze a richly contextualized problem and to propose and evaluate possible solutions (Derry \& Hmelo-Silver, 2005). Rather than being exemplars of how to apply theory into practice, problem-based learning cases are exemplars of real-life educational problems. Although the problem-based learning approach is increasingly popular among leading teachers and educational researchers (Williams, 1992; Williams \& Hmelo, 1998), our focus in the present study was the use of classroom cases in their former instructional function, namely, as exemplars or models of good teaching practices.

There are, however, variations among the kinds of cases used to accomplish the instructional objectives described above. For example, many educational psychology textbooks that are currently adopted in teacher education programs include narratives of classroom cases as part of their instructional materials (Borich \& Tombari, 1997; Dembo, 1994; Eggen \& Kauchak, 2004; Fetsco \& McClure, 2005; Ormrod, 2004; Santrock, 2006; Slavin, 2003; Woolfolk, 2004). A large number of video cases also convey more of the complexity of classroom events, with interactive, multimedia cases and hypermedia environments providing the richest situated materials (Beck, King, \& Marshall, 2002; Lampert \& Ball, 1998; Lampert, Heaton, \& Ball, 1994; Richardson \& Kile, 1999). In the present research, we investigated students' learning and perceptions about learning when presented with exemplar cases in both video and text formats.

What do we know about learning from cases in teacher education? Lundeberg, Levin, and Harrington (1999) presented a comprehensive review of the research base for teaching and learning with cases, with an emphasis on the use of written classroom dilemmas as tools to promote transfer of knowledge and critical thinking. For example, classroom dilemmas contribute to preservice teachers' discoveries of knowledge about the complexity of teaching and the diversity of learners and enable them to think critically about cases and propose courses of action (Lundeberg, 1999), with case discussions playing an important role in fostering inservice teachers' professional autonomy (Barnett \& Tyson, 1999). In addition, students' written analyses of classroom cases provide insight into changes about how they make reasoned decisions, warrant claims, and reflect on assumptions when solving these dilemmas over time (Harrington, 1999). An important contribution of past research is having identified three factors that influence the educative power of classroom dilemmas: their integration within the context of the specific classroom, a discussion activity following the presentation of the classroom dilemma, and the presence of a facilitator to guide the case discussions (Levin, 1999).

The role of using cases as exemplars rather than dilemmas in teacher education and the cognitive and affective consequences of presenting them in different presentation formats are less understood. On one hand, there is considerable evidence that familiar examples can serve as models that can be used in new situations (Dunbar, 1995), and that students learn procedural knowledge by observing how their teachers perform on different tasks (Braaksma, Rijlaarsdam, \& van den Bergh, 2002). On the other hand, although advocates of a social-cognitive theory of learning have shown that people are also influenced by models that are displayed by real or fictional characters in books, plays, movies, or television (Bandura, 1986), the study of the effects of symbolic modeling on teacher education has not received sufficient atten- tion. To our knowledge, there are no studies to date that have investigated the role of presenting classroom exemplars for teacher education in different formats.

The closest contribution to this research area is the work of Koehler and colleagues, who developed a set of case design principles to guide the development of hypermedia learning tools (Koehler \& Lehrer, 1998; Koehler, Petrosino, \& Lehrer, 1998). In his examination of two visions of what constitutes effective casebased hypermedia for mathematics teachers' professional development, Koehler (2002) compared learning from cases as episodes of classroom teaching, which are used to exemplify the big ideas of a domain, and cases as narratives, which highlight the development of learning and the causal relations between classroom episodes. Although both tools were found to be effective for acquiring knowledge, the two cases afforded differential support of knowledge in practice. Specifically, teachers' access to narrative cases afforded greater opportunities to organize and apply knowledge to an analysis of student work.

Our research builds on these efforts by investigating the cognitive and affective consequences of case exemplar design and is motivated by the need to develop tools that can help preservice teachers apply teaching principles to their practice. A good illustration of this need is the Stanford Teacher Education Program, which has developed online real-life classroom videos demonstrating good teaching practices for English language learners as part of the required California Cross-Cultural Language and Academic Development certification program (Bikle, Billings, \& Hakuta, 2003).

\section{Theoretical Framework and Research Questions}

In this section, we present the theoretical framework from which we derived the research questions for our study. Because we were interested in examining both the cognitive and affective consequences of our treatments, our theoretical framework integrates two theories. The first is case-based learning theory (Aamodt \& Plaza, 1994; Anderson, 1983; Dunbar, 1995; Kolodner, 1993; Ross, 1987; Schank, 1982), which describes the memory systems and cognitive processes involved in learning from cases. Second, we draw from a cognitive-affective theory of learning (Moreno, 2005; Pintrich, 2003), which describes how motivational, affective, and metacognitive factors mediate learning by increasing or decreasing cognitive engagement (Dewey, 1913; Moreno, 2005; Renninger, Hidi, \& Krapp, 1992). The main assumptions underlying case-based learning theory are

1. Case-based learning requires the dynamic use of a casebased memory system and a domain knowledge memory system (Schank, 1997).

2. Effective case-based learning includes the following set of cognitive processes (Armengol \& Plaza, 2003; Schank, 1997): a) extracting relevant information from the case using prior domain knowledge, b) indexing the case from relevant information, c) using the indexes to match a new case with similar cases stored in the learners' case-based memory, and d) transferring the information from similar cases to solve a new problem.

Past research in the area of case-based reasoning has lent support to these assumptions. For example, when people are presented 
with a new case to solve, they not only rely on general knowledge of a problem domain but also are able to retrieve similar past cases and reuse them in the new problem situation (Anderson, 1983; Ross, 1987). This finding is especially evident when the problem solver is an expert in the domain (Kolodner, 1993).

\section{Research Question 1: Does the Format of a Classroom Exemplar Affect Students' Recall of the Case Information?}

On the basis of the above-presented assumptions (a) and (b), we were interested in examining whether the classroom exemplar format would have an effect on students' retention of the information presented in the case. According to case-based learning theory, the stronger the case information is stored in students' case-based memory system, the more likely they will use the case information to think about future problem situations (Schank, 1997).

Video cases are media that can represent the complexity of classroom learning and teaching to its fullest degree, including subtleties that are difficult to express in writing (Putnam \& Borko, 2000), and video-specific representations of knowledge, such as temporal and emotional representations (Salomon, 1979). Thus, video cases convey a higher sense of authenticity than case narratives (Valmont, 1995), a level of realism that may result in denser memory traces than those resulting from reading a corresponding narrative (Wetzel, Radtke, \& Stern, 1994). Consequently, we predicted that prospective teachers who learn with a video case would outperform those who learn with a case narrative on immediate and delayed measures of retention.

\section{Research Question 2: Does the Presentation of a Classroom Exemplar Affect Students' Transfer?}

One of the most successful outcomes of instruction is the ability to use the newly learned information in diverse contexts, an ability commonly referred to as transfer (Salomon \& Perkins, 1989). According to the presented theoretical framework, as student teachers learn about educational psychology principles, they organize and integrate the new information with their prior domain knowledge. In addition, when students are given an example demonstrating how the learned principles can be applied to a specific classroom case, relevant aspects of the case are selected by matching the encoded principles with observed or described classroom behaviors (i.e., indexation process), and the new case is integrated with students' past case knowledge. By being presented with both the theoretical principles and an example of the application of such principles, students are able to construct a deeper understanding of the topic as compared with learning the theoretical principles alone. This, in turn, increases the likelihood of transferring the principles when students are presented with a new classroom scenario because of the preexisting connections between their theoretical knowledge and a similar classroom case (Bransford \& Schwartz, 1999). Therefore, case-based learning theory predicts that students who learn about an educational psychology topic with the presentation of a classroom exemplar will outperform those who learn about the same topic without the presentation of a classroom exemplar on immediate and delayed measures of transfer.
Research Question 3: Does the Presentation of a Classroom Exemplar and/or Exemplar Format Affect Students' Learning Perceptions?

Learning perceptions are noncognitive psychological outcomes resulting from a particular learning experience. Past research consistently has found favorable student perceptions when learning with a case pedagogy (Gentner, Loewenstein, \& Thompson, 2003; Lundeberg et al., 1999). Furthermore, the idea that learning with case exemplars may promote prospective teachers' positive learning perceptions is consistent with several motivation theories and research. In this regard, we hypothesized that presenting a classroom case during instruction would make prospective teachers perceive the learning experience as more meaningful and valuable to their professional goals (Schunk, 2000; Wigfield \& Eccles, 2000). This hypothesis is consistent with past research showing that preservice teachers prefer to learn from cases and are more motivated by learning from cases than from other traditional teaching methods (Barnett \& Tyson, 1999; Henry, Castek, Roberts, Coiro, \& Leu, 2004). In addition, authentic problems presented in realistic contexts have been shown to be motivating (Stepien \& Gallagher, 1993), and positive attitudinal effects have been found when preservice teachers learn with visual cases during computer networking instruction (Fitzgerald \& Semrau, 1998; Lacey \& Merseth, 1993; van den Berg et al., 2004). In sum, we predicted that students who learn without a classroom exemplar would report lower affective ratings than those who learn with a classroom exemplar, and that students who learn with a video case would rate the learning experience more favorably than those who learn with a classroom narrative.

\section{Experiment 1}

\section{Method}

\section{Participants and Design}

The participants were 53 preservice teachers enrolled in an introductory educational psychology course at a southwestern university. Participants were taking the course during the last semester of the teacher education program and were given credit for their participation in the study. There were 40 women and 13 men with a mean age of 26.67 years $(S D=9.19)$. The median age was 23 years. The reported ethnicities were 30 White Americans, 18 Hispanic Americans, 2 Native Americans, 2 Asian Americans, and 1 African American. There were 18 participants in the video and text groups and 17 participants in the control group. Comparisons were made between the video and text groups on measures of case retention and among the video, text, and control groups on measures of transfer and affective ratings.

\section{Materials and Apparatus}

For each participant, the paper-and-pencil materials consisted of a consent form, a debriefing form, a participant questionnaire, a pretest, a retention test, a transfer test, and a rating questionnaire, each typed on $8.5-\times 11$-in. sheets of paper. The purpose of the participant questionnaire was to gain information concerning the participant's name, gender, ethnicity, and age. The pretest (internal reliability of .81) was designed to measure the participant's knowledge of the topic. It contained 10 multiple-choice questions on the 
assigned educational psychology topic and was taken from the test bank corresponding to the adopted textbook (Eggen \& Kauchak, 2004). A pretest score was computed for each participant by adding all the correct responses on the 10-item multiple-choice test taken from the corresponding instructor test bank (Eggen \& Kauchak, 2004).

The retention test was administered to the video and text groups only. It was designed to examine whether the presentation format of the exemplar affected students' immediate and delayed retention of the factual information contained in the case and consisted of the following question: "Please write down everything you can remember about the double-column addition case you just (watched/read)." The retention test was scored using a rubric that included the factual information presented in the exemplar case. Retention scores were computed by counting the number of relevant statements that participants wrote on the retention test sheet (i.e., statements that were strongly tied to details and events presented in the video or case narrative). Case-unrelated statements were those having weak ties or were completely unrelated to the details and events presented in the video or case narrative, including such vague or off-task statements as "the video was quite good" or "I remember reading a classroom example." Caseunrelated statements also offered students' personal opinions about teaching and comments in which participants recognized their own difficulty recalling details from the case.

The transfer test was designed to examine whether the presentation of a classroom case exemplar, in which the application of the educational psychology principles learned to a classroom situation was illustrated, affected students' immediate and delayed transfer of those principles to a novel situation. It consisted of four questions that were each typed on a separate sheet and asked students to apply the learned principles to their own teaching practice. Two educational psychology instructors developed a rubric for scoring the transfer test questions. The final rubric, after several cycles of evaluation and revision, included a set of acceptable and unacceptable answers for each of the four transfer questions. Appendix A shows each transfer question and corresponding sample acceptable answers.

Students' unacceptable responses consisted of vague and inaccurate answers. Vague answers included responses that were not acceptable either because the answer was not complete or because it was ambiguously stated, such as "I would make sure I use a diversity of strategies" to answer Question 1, or "I guess it would depend on the type of learner" to answer Question 2. Inaccurate answers consisted of responses that showed misconceptions in the topic. Examples of inaccurate answers are "I would only ask questions that I knew students could answer quickly" to answer Question 3, and "I would present information to each learner according to their learning style" to answer Question 4. On the basis of the rubric, we computed a transfer score for each participant by counting the number of acceptable answers that the participant produced in the transfer test. Interrater reliability between the scorers was $90 \%$ for the retention test and $84 \%$ for the transfer test.

The rating questionnaire was a six-item instrument asking participants to rate their learning perceptions on a 10-point scale (internal reliability of .94). It was designed to assess and compare students' self-reported perceptions of learning with or without the presentation of a classroom case exemplar in video or text format. It contained the following questions: (a) "How interesting was it to learn about constructivism today?" $(1$ = boring; 10 = interesting $)$; (b) "How entertaining was it to learn about constructivism today?" $(1=$ tiresome $; 10=$ entertaining $)$; (c) "How eager would you be to learn about a different educational psychology topic in the same conditions you learned today?" $(1=$ not eager; 10 = very eager $)$; (d) "How motivating was it to learn about constructivism today?" $(1=$ not motivating; $10=$ very motivating $)$; (e) "How much did today's class help you understand the characteristics of constructivist classrooms?" ( $1=$ not at all; $10=$ very much); and (f) "How helpful was today's class for learning about constructivism?" $(1=$ unhelpful; $10=$ helpful). Using principal axis estimation, we found evidence for the valid aggregation of the six items into an aggregated factor-based scale (Pedhazur \& Schmelkin, 1991). Therefore, to maintain a score similar to that of the original six items (i.e., 10-point scale), we computed a mean affective rating score for each student by adding the scores from each of the six questionnaire items and dividing by 6 .

The classroom case materials for the video group consisted of a video case included in the educational psychology supplemental materials used by the participating instructors (Kamii, 2000). The video was part of the supplemental instructional materials designed to be presented during class when teaching about characteristics of constructivist classrooms. Unlike the shorter classroom stories provided at the beginning and end of each of the textbook's chapters (Eggen \& Kauchak, 2004), this 20-min video case showed a full lesson illustrating how an elementary teacher can apply constructivist principles and strategies to a mathematics classroom.

The classroom case materials for the text group were developed by two educational psychology instructors who were experienced in the use, development, and evaluation of case narratives. The narratives were based on the video case presented to the video group and on guidelines available in the qualitative research on teachers and teaching with cases (Shulman, 1992; Shulman \& Colbert, 1988). The final product consisted of a case narrative printed in a booklet that corresponded very closely to the video case. It had a comparable level of detail as the one offered in the video, including a thorough description of the contextual information depicting the classroom environment, artifacts, student and teacher characteristics, the exact dialogue between the teacher and students, and descriptions of nonverbal behaviors made explicit in the video. A significant effort was made to craft the narrative as an authentic story. A summary of the case and sample text are included in Appendix B. The apparatus consisted of a Sony VCR and TV system.

\section{Procedure}

First, immediately after the lecture on classroom assessments, all participants were given consent forms. Second, they took the pretest to assess their prior knowledge level. Third, participants were randomly assigned to a treatment group (video, text, or control). Fourth, the video and text groups were instructed to watch or read the exemplar case, and the control group was instructed to review the chapter that was covered during lecture for the same amount of time. All participants were informed that, once the time was over, they would be presented with a set of questions to assess their perceptions about learning and how much they had learned. Fifth, all participants were asked to answer the rating questionnaire at their own pace. Sixth, students in the video and 
text groups were given 5 min to answer the retention test. Seventh, all students were given $3 \mathrm{~min}$ to answer each question in the transfer test. Questions were presented one at a time, and participants worked individually on all tasks. Finally, 4 weeks later, during the last week of the semester, the participants were invited to the laboratory again for a retesting session during which students in the video and text groups retook the retention and transfer tests, and students in the control group retook the transfer test. Two independent scorers not aware of the treatment condition of each participant determined the pretest, rating, retention, and transfer scores.

\section{Results}

Statistical assumptions were evaluated and met. Alpha was set at .05 for all statistical tests and protected when conducting multiple tests. Table 1 shows the mean scores and corresponding standard deviations for the video, text, and control groups on measures of the pretest, retention and transfer tests, and ratings.

\section{Research Question 1: Does the Format of a Classroom Exemplar Affect Students' Recall of the Case Information?}

To answer this question, we subjected the data to a repeated measure analysis of variance (ANOVA) with treatment condition (video, text) as the between-subjects factor and immediate and delayed retention scores as the within-subject factor. The ANOVA revealed a significant main testing time effect and a significant main treatment effect. However, we found a significant interaction between testing time and treatment condition, $F(1,34)=4.30$, $M S E=1.49, p=.046$, partial $\eta^{2}=.11$; therefore, we chose to ignore the two main effects in favor of interpretation of the interaction.

We followed up on the significant interaction between testing time and treatment condition by examining the simple effects for the treatment factor within each of the two testing time occasions. As Table 1 shows, although the mean retention scores were not significantly different between text and video conditions on the immediate test, they were significantly lower for the text group than for the video group on the delayed measure, $F(1,34)=12.78$, $M S E=2.23, p=.001$, partial $\eta^{2}=.27$, showing a greater decrease on the retention measure for the text group.

\section{Research Question 2: Does the Presentation of a Classroom Exemplar Affect Students' Transfer?}

To answer this question, we conducted a repeated measure analysis of covariance (ANCOVA) with treatment condition (video, text, control) as the between-subjects factor, immediate and delayed transfer scores as the within-subject factor, and students' pretest score as a covariate. Although mean delayed transfer scores were lower than mean immediate transfer scores, the difference was not significant. However, we found a significant main effect for condition and a significant interaction between testing time and condition, $F(2,49)=5.15, M S E=6.72, p=.009$, partial $\eta^{2}=$ .17 .

Given the significant interaction between condition and testing time, we chose to ignore the treatment and time main effects and, instead, examined the simple main effect of testing time for each of the three treatment conditions. There was no significant change in transfer for any of the three conditions; therefore, we investigated the simple treatment effects within each of the two testing occasions. We found a significant difference in mean transfer among treatment groups immediately after the treatment, $F(2$, 49) $=9.87, M S E=19.04, p<.001$, partial $\eta^{2}=.29$, but differences on the delayed measure were not significant. We conducted post hoc means comparisons, using Tukey's HSD test, on the immediate measure and found that, immediately after the treatment, the video group produced higher transfer scores than both the text group and the control group $(p=.015$ and $p<.001$, respectively). No other significant pairwise differences were found.

\section{Research Question 3: Does the Presentation of a Classroom Exemplar or Classroom Exemplar Format Affect Students' Learning Perceptions?}

To answer this question, we compared students' rating scores in the three conditions with a one-way ANOVA, using treatment condition (video, text, control) as the between-subjects factor and students' rating score as the dependent variable. The ANOVA revealed a significant difference between treatment groups, $F(2$, $50)=11.32, M S E=2.49, p<.001$, partial $\eta^{2}=.31$. Post hoc means comparisons with Tukey's HSD tests indicated that the video group had significantly higher mean ratings than both the text group and control group $(p=.003$ and $p<.001$, respectively). The text group and control group did not differ significantly from one another.

\section{Experiment 2}

Our main goal in Experiment 2 was to investigate whether the pattern of results found in our first study would replicate in a second study using a different topic and a different group of students. If so, an additional goal of this experiment was to

Table 1

Experiment 1: Means and Standard Deviations on Pretest, Retention and Transfer Tests, and Affective Ratings for Three Groups

\begin{tabular}{|c|c|c|c|c|c|c|c|c|c|c|c|c|}
\hline \multirow[b]{3}{*}{ Group } & \multirow{2}{*}{\multicolumn{2}{|c|}{$\frac{\text { Pretest }}{\text { Immediate }}$}} & \multicolumn{4}{|c|}{ Retention } & \multicolumn{4}{|c|}{ Transfer } & \multirow{2}{*}{\multicolumn{2}{|c|}{$\begin{array}{c}\text { Ratings } \\
\text { Immediate }\end{array}$}} \\
\hline & & & \multicolumn{2}{|c|}{ Immediate } & \multicolumn{2}{|c|}{ Delayed } & \multicolumn{2}{|c|}{ Immediate } & \multicolumn{2}{|c|}{ Delayed } & & \\
\hline & $M$ & $S D$ & $M$ & $S D$ & $M$ & $S D$ & $M$ & $S D$ & $M$ & $S D$ & $M$ & $S D$ \\
\hline Video & 6.56 & 1.42 & 6.64 & 2.53 & 4.58 & 1.73 & 16.72 & 4.96 & 13.67 & 4.74 & 8.93 & 1.33 \\
\hline Text & 6.39 & 1.61 & 6.06 & 1.42 & 2.81 & 1.20 & 12.56 & 4.11 & 11.06 & 4.05 & 7.11 & 1.50 \\
\hline Control & 7.65 & 1.41 & & & & & 10.12 & 3.79 & 10.88 & 2.98 & 6.50 & 1.87 \\
\hline
\end{tabular}

Note. Scores ranged from 0 to 13 for the retention test, from 0 to 19 for the transfer test, and from 3 to 10 for the affective rating scores. 
conduct a qualitative analysis of students' responses to the retention and transfer tests to better understand the relationship between these measures and also help explain the differences found between the text and video conditions.

\section{Method}

\section{Participants and Design}

The participants were 55 preservice teachers enrolled in an introductory educational psychology course at a southwestern university (43 women and 12 men), who were given credit for their participation in the study. In accordance with the requirements of the university's college of education, students were taking the course during the last semester of the teacher education program. The mean age of the participants was 28.62 years $(S D=12.21)$, and the median age was 24 years. The reported ethnicities were 34 White Americans, 17 Hispanic Americans, 3 Native Americans, 1 Asian American, and 1 African American. There were 19 participants in the video and text groups and 17 participants in the control group. Comparisons were made between the video and text groups on measures of case retention and among the video, text, and control groups on measures of transfer and affective ratings.

\section{Materials and Apparatus}

The consent form, debriefing form, participant questionnaire, and retention test were identical to those used in Experiment 1. The pretest (internal reliability $=.79$ ) was identical to the one used in Experiment 1, except that the content was modified to coincide with the assigned educational psychology topic, and items were taken from the test bank corresponding to a different adopted textbook (Woolfolk, 2004). The transfer test also was modified to align with the topic chosen for this experiment (see Appendix C).

The rating questionnaire contained the same six questions described in Experiment 1, except that we substituted the word constructivism with the words grading rubrics. The factor-based rating score was computed using the same approach described in Experiment 1. Interrater reliabilities between the scorers were $91 \%$ for the retention test and $82 \%$ for the transfer test.

The classroom case materials for the video group consisted of a video case and part of the instructor's supplemental instructional materials (Woolfolk, 2001). Unlike the exemplars provided in the textbook adopted by the participating instructors, which were narrow snippets of text including a brief description of expert teachers' activities related to a question posed in the text, this 20-min classroom video showed a complete teacher lesson illustrating how to apply grading rubric principles when developing a performance classroom assessment, which was designed to be presented in class when teaching about classroom assessment. A summary of the case and sample text are included in Appendix D. The classroom case materials for the text group were developed using the same procedure and guidelines as those described in Experiment 1.

\section{Procedure}

The procedure was identical to the one used in Experiment 1.

\section{Results}

Table 2 shows the mean scores and corresponding standard deviations for the video, text, and control groups on measures of the pretest, retention and transfer tests, and ratings.

\section{Research Question 1: Does the Format of a Classroom Exemplar Affect Students' Recall of the Case Information?}

A repeated measure ANOVA with treatment condition (video, text) as the between-subjects factor and immediate and delayed retention scores as the within-subject factor revealed a significant main testing time effect and a significant main effect for condition. However, a significant interaction was noted between condition and time, $F(1,36)=9.47, M S E=3.41, p=.004$, partial $\eta^{2}=.21$. We, therefore, ignored interpretation of the main effects and followed up on the significant interaction between testing time and treatment condition by examining the simple effects for the treatment factor within each of the two testing time occasions.

As can be seen from Table 2, although the mean retention scores were not significantly different between text and video conditions on the immediate test, they were significantly lower for the text group than video group on the delayed measure, $F(1,36)=11.89$, $M S E=13.4, p=.002$, partial $\eta^{2}=.24$.

\section{Research Question 2: Does the Presentation of a Classroom Exemplar Affect Students' Transfer?}

A repeated measure ANCOVA with treatment condition as the between-subjects factor, immediate and delayed transfer scores as the within-subject factor, and students' pretest score as a covariate revealed a significant main testing time effect and a significant main effect for condition. A significant interaction between condition and testing time, $F(2,51)=6.66, M S E=4.97, p=.003$, partial $\eta^{2}=.21$, was also noted; given the significant interaction, we chose to ignore the treatment and time main effects and,

Table 2

Experiment 2: Means and Standard Deviations on the Pretest, Retention and Transfer Tests, and Affective Ratings for Three Groups

\begin{tabular}{|c|c|c|c|c|c|c|c|c|c|c|c|c|}
\hline \multirow[b]{3}{*}{ Group } & \multirow{2}{*}{\multicolumn{2}{|c|}{$\frac{\text { Pretest }}{\text { Immediate }}$}} & \multicolumn{4}{|c|}{ Retention } & \multicolumn{4}{|c|}{ Transfer } & \multirow{2}{*}{\multicolumn{2}{|c|}{$\begin{array}{c}\text { Ratings } \\
\text { Immediate }\end{array}$}} \\
\hline & & & \multicolumn{2}{|c|}{ Immediate } & \multicolumn{2}{|c|}{ Delayed } & \multicolumn{2}{|c|}{ Immediate } & \multicolumn{2}{|c|}{ Delayed } & & \\
\hline & $M$ & $S D$ & $M$ & $S D$ & $M$ & $S D$ & $M$ & $S D$ & $M$ & $S D$ & $M$ & $S D$ \\
\hline Video & 4.58 & 1.81 & 7.61 & 2.84 & 5.74 & 2.61 & 11.32 & 4.07 & 7.63 & 2.75 & 7.99 & 1.61 \\
\hline Text & 4.53 & 1.98 & 7.18 & 2.80 & 2.71 & 2.93 & 8.26 & 2.66 & 7.05 & 3.27 & 6.22 & 2.12 \\
\hline Control & 4.47 & 1.62 & & & & & 5.88 & 2.93 & 5.88 & 3.52 & 5.78 & 2.04 \\
\hline
\end{tabular}

Note. Scores ranged from 0 to 13 for the retention test, from 0 to 19 for the transfer test, and from 3 to 10 for the affective rating scores. 
instead, examined the simple main effect of the three treatment conditions within each level of time.

We found a significant difference in mean transfer among the three groups immediately after the treatment, $F(2,51)=12.10$, $M S E=11.03, p<.001$, partial $\eta^{2}=.32$, but differences on the delayed measure were not significant. Post hoc means comparisons with Tukey's HSD test were conduced on the immediate measure and showed that, immediately after the treatment, the video group produced higher transfer scores than both the text group and the control group ( $p=.017$ and $p<.001$, respectively). No other significant pairwise differences were found.

\section{Research Question 3: Does the Presentation of a Classroom Exemplar or Classroom Exemplar Format Affect Students' Learning Perceptions?}

To answer this question, we compared students' perceptions about learning in the three conditions with a one-way ANOVA, using treatment condition (video, text, control) as the betweensubjects factor and students' rating score as the dependent variable. The ANOVA revealed a significant difference between treatment groups, $F(2,52)=6.75, M S E=3.74, p=.002$, partial $\eta^{2}=.21$. Post hoc Tukey's HSD tests indicated that the video group had higher mean ratings than both the text and control groups, which did not differ from each other $(p=.018$ and $p=.003$, respectively).

In summary, the findings from Experiment 2 replicate the pattern of results found in Experiment 1 in three ways. Table 3 lists our predictions and summarizes the main findings of Experiments 1 and 2. First, we predicted that the video group would outperform the text group on immediate and delayed retention measures (Predictions 1 and 2). We found evidence in favor of presenting exemplars in video format from the retention measure. Although video and text groups showed comparable immediate case retention, the video group demonstrated more durable retention of the case information over time. Second, we predicted that presenting classroom case exemplars (text or video) would enable students to transfer knowledge to novel situations (Predictions 3 and 4). The video group also showed significant benefits over the control and text groups on immediate transfer of learning; however, such benefits disappeared 4 weeks later. Third, we predicted that case exemplar groups would produce higher affective ratings than the control group, and that the video group would show the highest affective ratings (Predictions 5 and 6). We found that students reported significantly higher positive ratings for learning with a video case exemplar compared with learning with a case narrative or no case presentation.

A puzzling finding across both experiments was that, although immediate recall of case exemplar information was similar for text and video groups, the video group had higher immediate transfer scores than the text group. In addition, although the video group had higher recall of the exemplar information than the text group on the delayed retention measure, the delayed transfer scores of the video group did not differ from the text group. According to case-based theories of learning, when students are presented with new problem-solving scenarios, they rely on their memory of similar past cases in addition to their general knowledge of the problem domains to solve the problem (Anderson, 1983; Ross, 1987). Why did the retention and transfer measures not show the relationship assumed by our theoretical framework? To answer this question, we decided to embark on an additional qualitative analysis using the data from Experiment 2 . We felt it would be beneficial to examine whether group differences in patterns of responses to the retention and transfer tests could offer a better understanding of the relationship between these measures and also help explain the differences found between the text and video conditions.

\section{Qualitative Analysis on Students' Case Retention Responses}

Coding. On the basis of the assumption that effective casebased learning requires extracting relevant information from the case, we focused on the set of acceptable answers to the retention

Table 3

Experiments 1 and 2: Predictions and Corresponding Findings

\begin{tabular}{|c|c|c|c|}
\hline \multirow[b]{2}{*}{ Prediction } & \multirow[b]{2}{*}{ Conclusion } & \multicolumn{2}{|c|}{ Effect size } \\
\hline & & Experiment 1 & Experiment 2 \\
\hline $\begin{array}{l}\text { 1. Video group will outperform the text group on immediate } \\
\text { measures of case retention }\end{array}$ & Not supported & .30 & .15 \\
\hline $\begin{array}{l}\text { 2. Video group will outperform the text group on delayed measures } \\
\text { of case retention }\end{array}$ & Supported & 1.21 & 1.09 \\
\hline \multicolumn{4}{|l|}{$\begin{array}{l}\text { 3. Case exemplar groups will outperform the control group on } \\
\text { immediate measures of transfer }\end{array}$} \\
\hline Text group & Not supported & .56 & .72 \\
\hline Video group & Supported & 1.51 & 1.65 \\
\hline \multicolumn{4}{|l|}{$\begin{array}{l}\text { 4. Case exemplar groups will outperform the control group on } \\
\text { delayed measures of transfer }\end{array}$} \\
\hline Text group & Not supported & .04 & .37 \\
\hline Video group & Not supported & .69 & .55 \\
\hline \multicolumn{4}{|l|}{$\begin{array}{l}\text { 5. Case exemplar groups will report higher affective ratings than the } \\
\text { control group }\end{array}$} \\
\hline Text group & Not supported & .40 & .44 \\
\hline Video group & Supported & 1.80 & 1.38 \\
\hline $\begin{array}{l}\text { 6. Video group will report higher affective ratings than the text } \\
\text { group }\end{array}$ & Supported & 1.42 & .94 \\
\hline
\end{tabular}


test, namely, case-related statements. Consistent with case-based learning theory, we were interested in responses that could potentially aid students' transfer of the principles modeled by the exemplar. To this end, we assigned a response category to each of the acceptable statements produced in the retention test. Within the case-related statements, three subcategories emerged: (a) direct event - a statement describing a specific action portrayed by the exemplar, such as "the teacher wrote on the chalkboard"; (b) indirect event $-\mathrm{a}$ statement drawing inferences from specific actions portrayed by the exemplar, such as "the students agreed on a scoring of 1, 2, 3, 4, and 5"; and (c) summary-a statement that summarized the case without making specific descriptions of portrayed events, such as "the case was about learning to make rubrics."

Repeated measure ANOVAs with treatment conditions (text and video) as the between-subjects factor and testing time as the within-subject factor were conducted on the number of statements for each of the three related response categories. Alpha was set at .05 for all analyses and protected using a Bonferroni adjustment. The first six columns of Table 4 show the means and standard deviations for the immediate and delayed retention categories for the text and video groups.

Direct event statements. Comparisons made on the direct event statements showed a significant main effect for time, but the main effect for condition was not statistically significant. The time by condition interaction was significant, $F(1,36)=8.16, M S E=$ $2.58, p=.007$, partial $\eta^{2}=.19$. We further explored the interaction by conducting simple main effects of condition within the immediate and delayed measures and found no significant differences between groups. On the other hand, comparisons made for each condition on the repeated measure showed that, whereas the number of direct event statements for the video group remained unchanged over time, they decreased significantly over time for the text group, $t(18)=4.06, p=.001$.

Indirect event statements. Comparisons made on the indirect event statements revealed a significant main effect for time, $F(1$, 36) $=8.60, M S E=2.09, p=.006$, partial $\eta^{2}=.19$, showing more indirect event statements on the immediate measure than on the delayed measure. The main effects for condition and the time by condition interaction were not significant.

Summary statements. Comparisons made on students' summary statements did not show a main effect for time. The main effect for condition was significant, $F(1,36)=12.72, M S E=$ $3.60, p=.001$, partial $\eta^{2}=.26$, showing a greater number of summary statements for the video condition than for the text condition. The time by condition interaction was not significant.
Taken together, these findings suggest that the video presentation may have encouraged deeper representations of the exemplar behaviors (as demonstrated by the lack of decline for direct event recall) and more integrated representations (as demonstrated by the larger number of summary statements) than the text narrative. These findings are consistent with a prior study that compared students' immediate and delayed (7 days) recall of a story presented either in text or movie format (Baggett, 1979). Similar to our results, although immediate recall was similar in both presentation media, it deteriorated faster for text.

\section{Qualitative Analysis on Students' Transfer Responses}

Coding. Next, we developed response categories on the basis of the content of participants' written responses to the transfer test. Similar to the retention measure, we focused on students' acceptable answers. On the basis of a social-cognitive theory of learning (Bandura, 1986), we coded two types of responses within students' acceptable transfer answers: model answers and novel answers. Model answers included responses in which students transferred the strategies, methods, or behaviors modeled by the exemplar (described in the portrayed teacher behaviors section in Appendix D) to their own teaching area. Novel answers included acceptable responses in which students applied the principles learned in ways that were not modeled by the exemplar. From these data, we computed a model and novel transfer score for each participant by counting the number of model and novel answers produced in the transfer test, respectively.

Repeated measure ANOVAs with treatment conditions (text, video, control) as the between-subjects factor and testing time as the within-subject factor were conducted on the model and novel answer scores. Alpha was set at .05 for all analyses and protected using a Bonferroni adjustment. The last four columns of Table 4 show the means and standard deviations for the transfer qualitative coding categories (immediate and delayed) for the three treatment conditions.

Model answers. Comparisons made on students' model answers showed a significant main effect for time, a main effect for condition, and a significant time by condition interaction, $F(2$, $52)=7.15, M S E=4.08, p=.002$, partial $\eta^{2}=.22$. We explored the interaction by conducting simple main effects of condition within the immediate and delayed measures. This analysis showed a significant difference among the three treatment groups immediately after treatment, $F(2,52)=24.27, M S E=6.88, p<.001$, partial $\eta^{2}=.48$. Post hoc means comparisons using Tukey's HSD test showed that the video group produced significantly more

Table 4

Experiment 2: Means and Standard Deviations on Immediate and Delayed Retention and Transfer Qualitative Coding Categories

\begin{tabular}{|c|c|c|c|c|c|c|c|c|c|c|c|c|c|c|c|c|c|c|c|c|}
\hline \multirow[b]{4}{*}{ Group } & \multicolumn{12}{|c|}{ Retention } & \multicolumn{8}{|c|}{ Transfer } \\
\hline & \multicolumn{4}{|c|}{ Direct event statements } & \multicolumn{4}{|c|}{ Indirect event statements } & \multicolumn{4}{|c|}{ Summary statements } & \multicolumn{4}{|c|}{ Model answers } & \multicolumn{4}{|c|}{ Novel answers } \\
\hline & \multicolumn{2}{|c|}{ Immediate } & \multicolumn{2}{|c|}{ Delayed } & \multicolumn{2}{|c|}{ Immediate } & \multicolumn{2}{|c|}{ Delayed } & \multicolumn{2}{|c|}{ Immediate } & \multicolumn{2}{|c|}{ Delayed } & \multicolumn{2}{|c|}{ Immediate } & \multicolumn{2}{|c|}{ Delayed } & \multicolumn{2}{|c|}{ Immediate } & \multicolumn{2}{|c|}{ Delayed } \\
\hline & $M$ & $S D$ & $M$ & $S D$ & $M$ & $S D$ & $M$ & $S D$ & $M$ & $S D$ & $M$ & $S D$ & $M$ & $S D$ & $M$ & $S D$ & $M$ & $S D$ & $M$ & $S D$ \\
\hline Video & 2.00 & 2.60 & 2.00 & 2.31 & 3.11 & 3.35 & 2.21 & 4.43 & 1.68 & 2.03 & 1.89 & 1.94 & 8.37 & 3.70 & 4.95 & 2.55 & 2.95 & 1.13 & 2.68 & 2.03 \\
\hline Text & 3.68 & 2.50 & 1.58 & 2.87 & 1.32 & 1.60 & 0.26 & 0.56 & 0.26 & 0.65 & 0.21 & 0.92 & 5.00 & 1.70 & 3.47 & 2.32 & 3.26 & 1.48 & 3.58 & 1.43 \\
\hline Control & & & & & & & & & & & & & 2.29 & 1.93 & 2.47 & 2.03 & 3.59 & 1.50 & 3.41 & 2.24 \\
\hline
\end{tabular}


model answers than both the text and control groups $(p<.001)$, and the text group produced significantly more model answers than the control group ( $p=.003$ ). There were also significant differences among the groups on the delayed measure, $F(2,52)=$ 5.22, $M S E=5.38, p=.009$, partial $\eta^{2}=.17$. Post hoc Tukey's HSD tests showed that the video group produced significantly more model answers than the control group $(p=.002)$. No other significant pairwise differences were found. Comparisons made for each condition on the repeated measure showed that, whereas the number of model answers for the control group remained unchanged over time, it decreased significantly over time for the video and text groups ( $p=.001$ and $p=.014$, respectively).

Novel answers. Comparisons made on students' novel answers did not reveal significant main effects for time or condition and showed no significant interaction between time and condition.

In summary, the findings suggest that students who learn by observing or reading exemplar teaching strategies are more likely to transfer the modeled strategies to their own teaching experiences than those who learn without a teaching exemplar. In addition, video presentations appear to encourage more modeled answers than text narratives. Although both the video and text conditions showed a decline in transferring modeled answers over time, the text condition showed a much more rapid decline than the video condition.

\section{General Discussion}

\section{Theoretical Implications}

The results of this research support the theoretical framework presented in our introduction in several ways. First, as predicted by case-based learning theories (Aamodt \& Plaza, 1994; Schank, 1982), students who learned about the educational psychology topic with the presentation of a video exemplar outperformed those who learned about the same topic without the presentation of an exemplar on measures of immediate transfer. Although this advantage did not seem to extend to the case narrative group, an investigation of the relative contribution of model answers and novel answers to students' transfer test scores revealed that both exemplar groups produced significantly more model answers than the control group.

Second, the findings from our retention and transfer qualitative analyses suggest that stronger retention of relevant exemplar information increases the likelihood of using such information in future problem-solving situations (Anderson, 1983; Ross, 1987). The video group, the only exemplar group whose retention for direct events did not decay over time, also produced more model answers than the control group 4 weeks after the treatment. In sum, similar to research that examined the effects of models on academic skills (Braaksma et al., 2002), the participants who were presented with a model teacher illustrating how to apply the learned principles into her practice were more likely to transfer the modeled strategies to their own teaching areas than were those not presented with the model. This likelihood seems to depend on the strength of the memory for case-related information, which might be increased when the classroom exemplar is in the video format (Baggett, 1979). In this regard, it is noteworthy that only participants in the text condition expressed their frustration when trying to recall the case in our delayed retention test. For example, one student wrote, "I am having difficulty recalling what this was about. I can picture in my head students talking, but I can't see the words that were on the page."

Third, consistent with past motivational effects found for other media (Cennamo, 1993; Lester, Towns, \& Fitzgerald, 1999; Tang \& Isaacs, 1993), classroom video cases also produced a positive effect on students' perceptions about learning. This finding extends past research on the motivational effects of using video cases during instruction (Barnett \& Tyson, 1999; Henry et al., 2004) and is consistent with a cognitive-affective theory of learning (Dewey, 1913; Moreno, 2005; Pintrich, 2003; Renninger et al., 1992). The consistent results across the two experiments suggest that video cases may have specific characteristics that help students feel that learning is easier (Lumsdaine, 1961), more motivating (Schunk, 2000; Wigfield \& Eccles, 2000), or more helpful to their goals (Valmont, 1995). Whether the larger number of model answers produced by the video group is the result of enhanced memory, reduced cognitive load, or increased engagement is still an open question. More research is needed to better understand the relationship between students' affect, motivation, and cognition when learning with video exemplars.

\section{Practical Implications and Limitations}

A practical contribution of this research is to provide empirical data demonstrating the superiority of video cases over case narratives and to establish their effectiveness as an instructional tool to promote students' positive learning perceptions and transfer of modeled teacher behaviors. This implication is especially important to educational psychology instruction, as videotape players are readily available in virtually every educational setting in the United States (Wetzel et al., 1994), and many educational psychology textbooks include video cases as part of their supplemental instructional materials (Eggen \& Kauchak, 2004; Ormrod, 2004; Woolfolk, 2004). Furthermore, the practical implications extend to digital video clips or multimedia cases, which can be readily delivered through the Internet (Hewitt, Pedretti, Bencze, Vaillancourt, \& Yoon, 2003).

In addition, our results suggest that, to benefit from a classroom exemplar presentation (text or video), it is essential that one retain relevant elements from the exemplar. Therefore, a direct practical implication of this study is to point out the need to supplement the presentation of the classroom exemplar with instructional methods that promote students' retention of exemplar information. One such method is to engage students in small-group discussions after viewing or reading the exemplar. We believe that the text and video groups may have shown stronger and longer term learning effects had we included this activity in our treatments. Future research should examine the learning contribution of discussions around case exemplars because most of what is known about this topic is centered on the presentation of classroom dilemmas (Lundeberg et al., 1999).

Moreover, according to case-based learning theory, the likelihood of transferring what is learned from exemplars to novel situations increases as the number of cases stored in students' case-based memory increases (Schank, 1982). Although the finding that both exemplar groups produced significantly more model answers than the control group supports the idea that classroom exemplars promote transfer, it also suggests that students' flexibility to transfer teaching principles might be compromised when learning with few exemplars. For instance, according to cognitive 
flexibility theory (Spiro \& Jehng, 1990), instructional environments should present new concepts with a variety of examples and contexts to increase students' ability to transfer their knowledge to novel scenarios, an ability called cognitive flexibility. Therefore, another method to increase students' transfer ability and cognitive flexibility when learning from exemplars is to present multiple classroom scenarios illustrating the principles to be learned. An important limitation in our exemplar treatments is that we used only one case as an illustration of how to apply the theory into practice. What we have found in the present study is that, even when no additional pedagogies are offered in connection to viewing an exemplar video case that illustrates how to apply educational psychology principles to the teaching practice, students have long-term retention of the case that may serve as a frame of reference in memory for future teaching experiences. The question of how much more influential video cases would be if we had fully integrated them into class instruction or if they were to be combined with other classroom activities needs further investigation.

Finally, it is important to note that the implications of our study are also limited because learning measures were timed and, therefore, may have precluded students from further elaboration on the materials, and because we chose to present a classroom case with a specific function (i.e., as an exemplar), population (i.e., student teachers), and content domain (i.e., educational psychology). These limitations may also suggest useful directions for future empirical evaluation.

\section{References}

Aamodt, A., \& Plaza, E. (1994). Case-based reasoning: Foundational issues, methodological variations, and system approaches. Artificial Intelligence Communications, 7, 39-59.

Anderson, J. R. (1983). The architecture of cognition. Cambridge, MA: Harvard University Press.

Armengol, E., \& Plaza, E. (2003). Remembering similitude terms in case-based reasoning. Lecture Notes in Artificial Intelligence, 2734, 121-130.

Baggett, P. (1979). Structurally equivalent stories in movie and text and the effect of the medium on recall. Journal of Verbal Learning and Verbal Behavior, 18, 333-356.

Bandura, A. (1986). Social foundations of thought and action: A social cognitive theory. Upper Saddle River, NJ: Prentice Hall.

Barnett, C. (1991). Building a case-based curriculum to enhance the pedagogical content knowledge of mathematics teachers. Journal of Teacher Education, 42, 263-272.

Barnett, C., \& Tyson, P. (1999). Case methods and teacher change: Shifting authority to build autonomy. In M. Lundeberg, B. Levin, \& H. Harrington (Eds.), Who learns what from cases and how? The research base for teaching and learning with cases. (pp. 53-69). Mahwah, NJ: Erlbaum.

Beck, R. J., King, A., \& Marshall, S. K. (2002). Effects of videocase construction on preservice teachers' observations of teaching. The Journal of Experimental Education, 70, 345-361.

Bikle, K., Billings, E., \& Hakuta, K. (2003). Trends in two-way immersion research. In J. A. Banks \& C. A. M. Banks (Eds.), Handbook of research on multicultural education (2nd ed., pp. 589-606). New York: Macmillan.

Borich, G. D., \& Tombari, M. L. (1997). Educational psychology: A contemporary approach. Harlow, NY: Longman.

Borko, H., \& Putnam, R. T. (1998). The role of context in teacher learning and teacher education. In Contextual teaching and learning: Preparing teachers to enhance student success in the workplace and beyond. Information Series No. 376 (pp. 34-68). Columbus, OH: ERIC Clearinghouse on Adult, Career, and Vocational Education Center on Educa- tion and Training for Employment. (ERIC Document Reproduction Service No. ED429263)

Braaksma, M. A. H., Rijlaarsdam, G., \& van den Bergh, H. (2002). Observational learning and the effects of model-observer similarity. Journal of Educational Psychology, 94, 405-415.

Bransford, J. D., \& Schwartz, D. L. (1999). Rethinking transfer: A simple proposal with multiple implications. In A. Iran-Nejad \& P. D. Pearson (Eds.), Review of research in education (Vol. 24, pp. 61-100). Washington, DC: American Educational Research Association.

Cennamo, K. S. (1993). Learning from video. Factors influencing learners' preconceptions and invested mental effort. Educational Technology, Research, and Development, 41, 33-45.

Copeland, W. D., \& Decker, D. L. (1996). Video cases and the development of meaning making in preservice teachers. Teaching and Teacher Education, 12, 467-481.

Dembo, M. H. (1994). Applying educational psychology (5th ed.). White Plains, NY: Longman.

Derry, S. J., \& Hmelo-Silver, C. E. (2005). Reconceptualizing teacher education: Supporting case-based instructional problem solving on the World Wide Web. In L. PytlikZillig, M. Bodvarsson, \& R. Bruning (Eds.), Technology-based education: Bringing researchers and practitioners together (pp. 21-38). Greenwich, CT: Information Age Publishing.

Dewey, J. (1913). Interest and effort in education. Cambridge, MA: Houghton Mifflin.

Dunbar, K. (1995). How scientists really reason: Scientific reasoning in real-world laboratories. In R. J. Sternberg \& J. E. Davidson (Eds.), The nature of insight (pp. 365-395). Cambridge, MA: MIT Press.

Eggen, P., \& Kauchak, D. (2004). Educational psychology: Windows on classrooms. Upper Saddle River, NJ: Prentice Hall.

Fetsco, T., \& McClure, J. (2005). Educational psychology: An integrated approach to classroom decisions. Boston: Pearson Education.

Fitzgerald, G. E., \& Semrau, L. P. (1998). The effects of learner differences on usage patterns and learning outcomes with hypermedia case studies. Journal of Educational Multimedia and Hypermedia, 7, 309-341.

Gentner, D., Loewenstein, J., \& Thompson, L. (2003). Learning and transfer: A general role for analogical encoding. Journal of Educational Psychology, 95, 393-408.

Goodlad, J. (1990). Teachers for our nation's schools. San Francisco: Jossey-Bass.

Harrington, J. L. (1999). Discovering teaching and learning through cases. In M. Lundeberg, B. Levin, \& H. Harrington (Eds.), Who learns what from cases and how? The research base for teaching and learning with cases (pp. 29-51). Mahwah, NJ: Erlbaum.

Henry, L. A., Castek, J., Roberts, L., Coiro, J., \& Leu, D. J., Jr. (2004). Case technologies to enhance literacy learning: A new model for early literacy teacher preparation. Knowledge Quest, 33(2), 26-29.

Hewitt, J., Pedretti, E., Bencze, L., Vaillancourt, B., \& Yoon, S. (2003). New applications for multimedia cases: Promoting reflective practice in preservice teacher education. Journal of Technology and Teacher Education, 11, 483-500.

Holmes Group. (1995). Tomorrow's school of education: A report of the Holmes Group. East Lansing, MI: Author.

Kamii, C. (Producer). (2000). Double-column addition: A teacher uses Piaget's theory [Motion picture]. (Available from Teachers College Press, Columbia University, New York, NY 10027)

Koehler, M. J. (2002). Designing case-based hypermedia for developing understanding of children's mathematical reasoning. Cognition and Instruction, 20, 151-195.

Koehler, M. J., \& Lehrer, R. (1998). Designing a hypermedia tool for learning about children's mathematical cognition. Journal of Educational Computing Research, 18, 123-145.

Koehler, M. J., Petrosino, A. J., \& Lehrer, R. (1998). Designing cases for hypermedia environments in teacher education. In A. Bruckman, M. Guzdial, J. Kolodner, \& A. Ram (Eds.), Proceedings from the Interna- 
tional Conference of the Learning Sciences (pp. 324-325). Charlottesville, VA: Association for the Advancement of Computing in Education.

Kolodner, J. (1993). Case-based reasoning. San Francisco: Morgan Kauffman.

Kolodner, J. L., \& Guzdial, M. (2000). Theory and practice of case-based learning aids. In D. H. Jonassen \& S. M. Land (Eds.), Theoretical foundations of learning environments (pp. 215-242). Mahwah, NJ: Erlbaum.

Lacey, C. A., \& Merseth, K. K. (1993). Cases, hypermedia and computer networks: Three curricular innovations for teacher education. Journal of Curriculum Studies, 25, 543-551.

Laframboise, K. L., \& Griffith, P. L. (1997). Using literature cases to examine diversity issues with preservice teachers. Teaching and Teacher Education, 13, 369-382

Lampert, M., \& Ball, D. (1998). Investigating teaching: New pedagogies and new technologies for teacher education. New York: Teachers College Press.

Lampert, M., Heaton, R., \& Ball, D. (1994). Using technology to support a new pedagogy of mathematics teacher education. Journal of Special Education Technology, 12, 276-289.

Lester, J. C., Towns, S. G., \& Fitzgerald, P. J. (1999). Achieving affective impact: Visual emotive communication in lifelike pedagogical agents. International Journal of Artificial Intelligence in Education, 10, $278-$ 291.

Levin, B. B. (1999). The role of the facilitator in case discussions. In M. Lundeberg, B. Levin, \& H. Harrington (Eds.), Who learns what from cases and how? The research base for teaching and learning with cases (pp. 101-115). Mahwah, NJ: Erlbaum.

Lumsdaine, A. (1961). Instruments and media of instruction. In N. L. Gage (Ed.), Handbook of research on teaching (pp. 583-682). Chicago: Rand McNally.

Lundeberg, M. (1999). Discovering teaching and learning through cases. In M. Lundeberg, B. Levin, \& H. Harrington (Eds.), Who learns what from cases and how? The research base for teaching and learning with cases (pp. 3-23). Mahwah, NJ: Erlbaum.

Lundeberg, M. A., Levin, B. B., \& Harrington, H. L. (Eds.) (1999). Who learns what from cases and how? The research base for teaching and learning with cases. Mahwah, NJ: Erlbaum.

Merseth, K. (1991). The case for cases in teacher education. Washington, DC: American Association of Higher Education.

Merseth, K. K. (1999). Foreword: A rationale for case-based pedagogy in teacher preparation. In M. A. Lundeberg, B. B. Levin, \& H. L. Harrington (Eds.) Who learns what from cases and how? The research base for teaching and learning with cases (pp. ix-xv). Mahwah, NJ: Erlbaum.

Moreno, R. (2005). Instructional technology: Promise and pitfalls. In L. PytlikZillig, M. Bodvarsson, \& R. Bruning (Eds.), Technology-based education: Bringing researchers and practitioners together (pp. 1-19). Greenwich, CT: Information Age Publishing.

Ormrod, J. E. (2004). Educational psychology: Developing learners. Upper Saddle River, NJ: Prentice Hall.

Pedhazur, E. J., \& Schmelkin, L. P. (1991). Measurement design and analysis. Hillsdale, NJ: Erlbaum.

Pintrich, P. R. (2003). Motivation and classroom learning. In W. M. Reynolds \& G. E. Miller (Eds.), Handbook of psychology: Educational psychology (pp. 103-122). New York: Wiley.

Putnam, R., \& Borko, H. (2000). What do new views of knowledge and thinking have to say about research on teacher learning? Educational Researcher, 29, 4-15.

Renninger, K. A., Hidi, S., \& Krapp, A. (Eds.). (1992). The role of interest in learning and development. Hillsdale, NJ: Erlbaum.

Richardson, V., \& Kile, R. S. (1999). Learning from video-cases. In M. A. Lundeberg, B. B. Levin, \& H. L. Harrington (Eds.). Who learns what from cases and how? The research base for teaching and learning with cases. (pp. 121-136). Mahwah, NJ: Erlbaum.

Ross, B. H. (1987). This is like that: The use of earlier problems and the separation of similarity effects. Journal of Experimental Psychology: Learning, Memory, and Cognition, 13, 629-639.

Salomon, G. (1979). Interaction of media, cognition, and learning. San Francisco: Jossey-Bass.

Salomon, G., \& Perkins, D. N. (1989). Rocky roads to transfer: Rethinking mechanisms of a neglected phenomenon. Educational Psychologist, 24 $113-142$.

Santrock, J. W. (2006). Educational psychology classroom update: Preparing for PRAXIS and practice (2nd ed.). Boston: McGraw-Hill.

Schank, R. (1982). Dynamic memory: A theory of reminding and learning in computers and people. New York: Cambridge University Press.

Schank, R. (1997). Virtual learning. New York: McGraw-Hill.

Schunk, D. (2000). Learning theories (3rd ed.). Upper Saddle River, NJ: Merrill, Prentice Hall

Sears, S. J., \& Hersh, S. B. (1998). Contextual teaching and learning: An overview of the project. In Contextual teaching and learning: Preparing teachers to enhance student success in the workplace and beyond. Information Series No. 376 (pp. 1-16). Columbus, OH: ERIC Clearinghouse on Adult, Career, and Vocational Education Center on Education and Training for Employment. (ERIC Document Reproduction Service No. ED427263)

Shulman, J. H. (1992). Toward a pedagogy of cases. In J. H. Shulman (Ed.), Case methods in teacher education (pp. 1-30). New York: Teachers College Press.

Shulman, J. H., \& Colbert, J. A. (Eds.). (1988). The intern teacher casebook. Washington, DC: ERIC Clearinghouse on Teacher Education. (ERIC Document Reproduction Service No. ED296998)

Slavin, R. E. (2003). Educational psychology: Theory and practice (7th ed.). Boston: Pearson Education.

Spiro, R. J., \& Jehng, J. C. (1990). Cognitive flexibility and hypertext: Theory and technology for the nonlinear and multidimensional traversal of complex subject matter. In D. Nix \& R. Spiro (Eds.), Cognition, education, and multimedia: Exploring ideas in high technology (pp. 163-205). Hillsdale, NJ: Erlbaum.

Stepien, W., \& Gallagher, S. (1993). Problem-based learning: As authentic as it gets. Educational Leadership, 50, 25-28.

Sykes, G., \& Bird, T. (1992). Teacher education and the case idea. In G. Grant (Ed.), Review of research in education (Vol. 18, pp. 457-521). Washington, DC: American Educational Research Association.

Tang, J. C., \& Isaacs, E. (1993). Why do users like video? Studies of multimedia-supported collaboration. Computer-Supported Cooperative Work: An International Journal, 1, 163-196.

Valmont, W. J. (1995). Creating videos for school use. Boston: Allyn \& Bacon.

van den Berg, E., Jansen, L., \& Blijleven, P. (2004). Learning with multimedia cases: An evaluation study. Journal of Technology and Teacher Education, 12, 491-509.

Wetzel, C. D., Radtke, P. H., \& Stern, H. W. (1994). Instructional effectiveness of video media. Hillsdale, NJ: Erlbaum.

Whitehead, A. N. (1929). The aims of education. New York: Macmillan. Wigfield, A., \& Eccles, J. (2000). Expectancy-value theory of achievement motivation. Contemporary Educational Psychology, 25, 68-81.

Wilkerson, L., \& Gijselaers, W. H. (1996). Bridging problem-based learning to higher education: Theory and practice. San Francisco: JosseyBass.

Williams, S. M. (1992). Putting case-based instruction into context: Examples from legal and medical education. The Journal of the Learning Sciences, 2, 367-427.

Williams, S. M., \& Hmelo, C. E. (Eds.). (1998). Special issue: Learning through problem solving. The Journal of the Learning Sciences, 7.

Woolfolk, A. (2001). Educational psychology (8th ed.). Developing a grading rubric [CD-ROM video clip]. (Available from Allyn \& Bacon, 160 Gould Street, Needham Heights, MA 02494)

Woolfolk, A. (2004). Educational psychology. Needham Heights, MA: Allyn \& Bacon. 


\section{Appendix A}

Transfer Questions Used in Experiment 1 and Sample Acceptable Answers

What constructivist methods can you use to encourage your students to develop their own strategies?

Would you ask your students to explain and defend their thinking about a problem to the entire class? What are the advantages of doing or not doing so?

Give examples of effective questions that you can ask during lessons that are based on constructivist views of learning and justify your answer.

Describe what kind of strategies you might use to promote constructivist learning in your teaching area. Please illustrate each strategy with a concrete example.
Have students think about a problem out loud and use prompts to help them find a method to solve it.

An advantage to having students explain their thinking is that it does not focus on learning products alone but values the process of learning.

I would ask high order questions that require deeper processing of the new information and open ended questions that may not have a right or wrong answer.

Assign a book that raises a debate or controversy about a topic, and ask students to take one of the positions and write an essay in their support.

\section{Appendix B}

\section{Summary of Case Exemplar Used in Experiment 1}

\section{Topic}

A second-grade teacher guides her students to discover how to solve double-column addition problems.

\section{Portrayed Teacher Behaviors}

Writes on the board a double-column addition problem.

Asks students to raise their hands if they have found a way to get the answer.

Praises students for raising their hands.

Gives ample wait time until most of the class has raised its hands.

Calls on the student who raised his hand first.
Asks the student to explain his way of finding the answer to the problem.

Writes the answer on the board.

Asks the rest of the class how many agree with the student's response.

Asks if there is anybody that disagrees with the student's response.

For all students who agreed, she inquires if they used a different strategy.

Those who used a different strategy are asked to explain the strategy to the rest of the class.

Repeats this process with other problems until students master double-column addition.

\section{Appendix C}

Transfer Questions Used in Experiment 2 and Sample Acceptable Answers

\section{Transfer Question}

What strategies can you use to encourage your students to participate in the design of a grading rubric?

How would you design a grading rubric to promote students' self regulation?

Would you ask your students to evaluate others' performance? What are the advantages of doing or not doing so?

Describe what kind of categories you might use in a grading rubric to assess your students' learning or performance.
Sample Acceptable Answer

Engage students in a discussion about what are the different aspects that a certain learning product should be evaluated on.

Include sections in the rubric where students are asked to rate their own learning process and products.

I would because asking students to grade others' work promotes their understanding of the learning objectives.

Some categories I would use are clarity of writing, organization of the subject, grammar, and spelling (for a prospective English teacher). 


\section{Appendix D}

Summary of Case Exemplar Used in Experiment 2

\section{Topic}

A middle school math teacher works with her students to develop a grading rubric for a tessellation project.

\section{Portrayed Teacher Behaviors}

Asks the class to define the term tessellation.

Shows the students a posterboard with a colorful tessellation design and title.

Identifies the characteristics of the tessellation definition on the design.

Explains how the tessellation was made and the difficulty of the project.

Specifies the objective of the lesson: to design a grading rubric for a tessellation project. Asks students which categories should be included in the rubric.

Writes on the board students' category suggestions.

Asks students how categories should be quantified in the rubric.

Guides a discussion about the issue if students' effort should be quantified in the rubric.
Calls a few students to the board and asks them to organize the list under bigger categories.

After all categories are organized, teacher suggests additional ideas.

Guides a discussion about the point system to be included in the rubric.

Explains conversion of points to percentages.

Finds agreement on a 5-point rating for each category.

Informs students that she will type up the grading rubric developed by the class.

Asks the class if there is anything else they would like to add to the rubric design.

Shows again the posterboard with the tessellation and asks students to grade it using the rubric.

Received January 6, 2006

Revision received October 19, 2006

Accepted October 23, 2006 